\title{
Effect of Electromagnetic Radiation Emanating from the Human Mind on Brain Tumor
}

\section{Chaudhuri TK ${ }^{1 *}$, Chowdhury TK ${ }^{2}$ and Chaudhuri TR}

${ }^{1}$ Eastern Virginia Medical school, Norfolk, Virginia, USA

${ }^{2}$ University of Oklahoma Health Sciences Center, Oklahoma, USA

${ }^{3}$ Department of Radiology, University of Alabama at Birmingham, Alabama, USA

The beneficial effect of prayer as the positive outcome of medical illness is well established in the literature [1-4]. However, the mechanism of action of prayer on positive recovery from medical illness had remained unknown. Therefore, people had been calling the positive effect of prayer on medical illness as 'medical miracle'.

Chaudhuri and his team of scientists, doctors and divine mentor [5] theorized for the first time that the beneficial effect of prayer, worship and meditation (PWM) on medical illness is mediated through the Electromagnetic Energy (EME) of the Human Mind [5].

A 40 year old male had one month history of headache and seizure secondary to a small pea-size tumor in the left frontal lobe of his brain without metastases as revealed by the CT scan. He refused all conventional medical treatment - surgery, radiation therapy, chemotherapy etc. Although the presentation of CT scan images would have been helpful but unfortunately the CT scan images are not available because the case is 20 years old and was from India where majority of patients resort to WPM for recovery from illness.

Instead he resorted to spiritual therapy - daily worship, prayer and meditation (WPM). Following three months of this spiritual therapy, a repeat CT scan revealed partial regression of the brain tumor from pea-size to pin-head size with improvement of headache and seizure.

Chaudhuri and his team [5] propose that the mechanism of action of worship, prayer and meditation (WPM) on regression of brain tumor and recovery from other medical illnesses is mediated through the electromagnetic energy (EME) or electromagnetic radiation (EMR) emanating from the human mind during worship, prayer and meditation (WPM).

The EME of the human mind is a non-ionizing radiation and falls in the same region in the Electromagnetic Spectrum as the EME of iPhone, texting, router, and Wi-Fi.

Further studies are needed to confirm Chaudhuri's theory and to characterize the nature of the EMR originating from the human mind. There also exists the need for the invention of a machine that could detect and measure the strength of the EME of the human mind with and without WPM.

The EME of the human mind is so powerful that it not only plays a role in recovering from medical illness, but it also plays an important role in the following events of human life :

1. in maintaining the entire human life from conception to death,

2. in causing disease, disability, and death (3 D's),

This article was originally published in a special issue, Radiation Oncology and Radiobiology handled by Editor(s). Richard Maximus Fleming, The Camelot Foundation, United States
3. in establishing bonding between human beings - between loved ones, between less-loved ones and between non-loved ones,

4. in causing human sufferings and happiness, and

5. in making people rich and poor

Every second of human life, EME flows through human mind. With WPM, this EME or EMR increases in intensity thus causing beneficial effect on the recovery from illness - in this case - regression of brain tumor in very early stage.

The EME or EMR of human mind works on the principles of particle physics and quantum mechanics. The EME or EMR of human mind also explains how the human mind and soul develop at conception, and how the mind of the child mirrors the minds of the parents [5]. The EMR of human mind works wirelessly like the EMR of the smart phone, router, and $\mathrm{Wi}-\mathrm{Fi}$.

So far we had a detailed understanding of the origin of the physical body of human being through the physiological science of 'Embryology', now we have the understanding of the origin of the human mind and soul through the science of particle physics and quantum physics. Now we also have the understanding of mechanism of regression of brain tumor by worship, prayer, and meditation.

\section{References}

1. Dusek JA, Sherwood JB, Friedman R, Myers P, Bethea CF, et al. (2002) Study of the therapeutic effects of intercessory prayer (STEP): Study design and research methods. Am Heart J 143: 577-584.

2. Leibovici L (2001) Effects of remote, retroactive intercessory prayer on outcomes in patients with bloodstream infection: In randomized controlled trial BMJ 323: 1450-1451.

3. Bonadonna R (2003) Meditation's impact on chronic illness. Holist Nurs Pract 17: $309-319$

4. Richmond JA, Bailey DE, Jr., McHutchison JG, Muir AJ (2010) The use of mind-body medicine and prayer among adult patients with chronic hepatitis $\mathrm{C}$. Gastroenterol Nurs 33: 210-216.

5. Chaudhuri TK, Chowdhury TK, Chaudhuri TR, Chowdhury TK, Chowdhury BR (2017) Electromagnetic Energy of the Human Mind. Createspace.

*Corresponding author: Chaudhuri TK, P.O.Box: 3323, Hampton, Virginia -23663, USA. Tel: 757-593-4798; E-mail: tkchaudhuri44@gmail.com

Received March 15, 2018;Accepted April 16, 2018;Published April 20,2018

Citation: Chaudhuri TK, Chowdhury TK, Chaudhuri TR (2018) Effect of Electromagnetic Radiation Emanating from the Human Mind on Brain Tumor. J Nucl Med Radiat Ther S9: 004. doi: 10.4172/2155-9619.S9-004

Copyright: $\odot 2018$ Chaudhuri TK, et al. This is an open-access article distributed under the terms of the Creative Commons Attribution License, which permits unrestricted use, distribution, and reproduction in any medium, provided the original author and source are credited. 